\title{
关于天气预报准确率影响因素及其策略的探讨
}

\author{
王一淞张磊陆晓平 \\ 前郭县气象局 \\ DOI:10.32629/as.v1i4.1492
}

[摘 要] 天气预报准确率是确保气象事业长远健康发展的前提,及时有效的预报极端恶劣天气, 可以尽最大可能保护其生命 财产安全, 降低人民群众的经济损失。随着社会经济的快速发展, 人们对气象预报要求的标准也越来越高。因此为了保障天气 预报准确率,本文阐述了天气预报的主要特征,对天气预报准确率的影响因素及其策略进行了探讨分析。

[关键词] 天气预报; 特征; 准确率; 影响因素; 策略

天气预报对人们日常工作、生活以及出行等方面具有重 要影响, 特别是有一些极端恶劣天气, 比如说台风、暴雨以及 冰冻等破坏性都比较大, 如果预报不准确就会给人们生活带 来比较严重的损失, 因此必须提高天气预报准确率。以下就 天气预报准确率的影响因素及其策略进行了探讨分析。

\section{1 天气预报的主要特征}

天气预报是应用大气变化的规律, 根据当前及近期的天 气形势, 对某一地未来一定时期内的天气状况进行预测。它 是根据对卫星云图和天气图的分析, 结合有关气象资料、地 形和季节特点、群众经验等综合研究后作出。天气预报的主 要特征。(1) 时效性和针对性特征。过去天气预报信息从制 作到播出必須要经过非常多的复杂环节, 很容易降低天气预 报的时效性和针对性。而短时和临近天气预报能够快速地针 对最新的气象资料进行分析, 并且利用计算机等平台进行快 速专业处理, 及时发布天气预报信息, 避免了天气信息制作 到播出的时间差异, 及时为广大群众提供准确的天气信息, 有效提高了防灾减灾的效果。近年来全球天气变化异常, 极 端天气出现越来越频繁, 对于农业的生产生活产生了巨大的 影响, 为此必须积极通过天气预报指导农业生产, 同时起到 防灾减灾的作用。气象部门需要结合农业生产的特点, 根据 不同农作物对于气象条件的不同要求, 提供针对性的气象服 务, 保障农业发展和粮食安全, 促进我国农业经济平稳发展。 (2) 精准性特征。天气预报的准确率随着时效的长短变化而 变化。通常情况下, 天气预报的时效越长, 则预报的准确率越 低, 时效越短, 则预报的准确率越高, 天气资料获取越精准, 越容易掌握天气的演变趋势, 与过去相比, 天气预报的准确 度越来越高。借助现代化的气象信息收集设备, 气象部门能 够随时随地地收集所需要的气象资料, 然后通过相关的信息 技术分析软件, 能够把握天气变化的规律, 从而能够准确预 报短时性天气。

\section{2 天气预报准确率的主要影响因素分析}

天气预报准确率的影响因素主要有: (1) 预报方法因素。 天气预报方法不足的情况一般都存在于基层气象站台中, 基 层业务人员缺少天气预报的相关工作经验, 又没有科学分析 天气预报的方法和相关科技, 所以基层经常存在天气预报准
确率不高的现象。(2) 环境因素。在天气预报过程中, 如果气 象监测的清晰度和精确度越高, 那么天气预报的准确率就越 高。目前, 我国在气象观测方面还存在诸多问题, 需要认真对 待。比如说, 随着城市化的深入发展, 空气污染严重, 楼房高 笪入云, 当对某一区域进行观测时, 由于空气混浊或者建筑 物的遮挡, 无法及时准确的进行气象观测, 从而大大降低了 预报的准确性。气象观测站大多都被安置在城镇区域内, 但 是随着城市化进程不断加快, 由于城市规划等因素的影响, 部分气象观测站不得不撤离原地, 这就造成观测过程出现间 断, 直接影响到该领域天气播报的整体质量。(3) 缺乏系统分 析的因素。要想提高天气预报的准确率, 就必须系统分析这 些影响因素, 如果在天气预报中缺少专业理论支撑以及可靠 的科学依据, 那么播报内容自然缺少可信度。在具体分析某 一地区的天气过程中, 预报业务人员没有正确认识并且分析 影响预报准确性的因素就会影响到最后预报的准确率, 四季 变化、地形地势、地方风貌、风向风速以及城市热效应等都 是影响一个地区天气变化的主要因素, 大多数预报业务人员 没有对这些因素进行系统的分析, 大多是凭借自己的经验和 猜测得出的结果, 所以准确率不高。(4) 从业人员因素。在完 成比较精确的气象观测之后, 预报业务人员需要通过自身的 专业知识进行数据分析以及应用, 从而得出数据比较精准的 天气预报。目前, 随着全球变暖, 各地恶劣天气频繁出现, 我国 的预报业务人员面对如此复杂的天气问题, 无从下手。预报业 务人员分析得出的结果都需要经过实际情况来验证, 一旦预 报业务人员没有跟上数据分析, 就会严重影响到天气预报的 准确性。天气预报的原理就是通过观测掌握大气运动的主要 规律及其相关数据, 工作人员再根据自己的专业技能对这些 规律以及数据进行分类整理, 最后得出结果。由于天气预报工 作人员专业技术存在不足, 导致天气预报的准确率无法提高。

\section{3 提高天气预报准确率的策略}

3.1 严格运行数据分析式的预报模式。数据分析是现代 天气预报工作进行的前提和基础, 可以将 GIS 气候因子纳入 提高相应气象预报准确率的范畴内。近年来, 随着层出不穷 推出的集合预报产品应用得越发成熟, 可以考虑构建起一个 在国家、省市、县镇三级应用起来的平台, 而后在订正制作、 
分析指导乃至是后期的评估上多下功夫, 由此总结出一套适 合于本地区气象预报的明确的指标体系作为有效提高气象 预报的准确率的数值依据, 进而提升天气预报的准确率。

3.2 建立健全完善气象观测工作。气象观测受到环境因 素的影响比较大, 这是客观规律, 就目前科学技术而言, 还无 法缓解这个状况, 因此预报业务人员需要不断完善气象观测 工作, 对干扰因素较多的地方加大监测力度, 对需要搬迁的 气象观测站, 相关部门可以充分利用网络媒体参考其他区域 的天气预报。不断完善各种恶劣天气的相关资料, 对其天气 图以及强度变化等做记录并且保留, 以备恶劣天气预警, 以 此着力提高天气预报的准确率。

3.3 充分运用先进的观测技术与观测方法。原始的人工 监测局限性比较大, 导致预报结果精确度比较低, 因此各地方 气象观测站应该加大资金投入, 积极引进先进的气象观测技 术, 对负责区域进行全天候 24 小时的监测, 由机器进行监测所 得出的数据科学性比较高, 并且保持机器监测连续不间断, 为 后期分析提供一连串的相关数据, 确保数据分析准确。不断创 新观测方法, 在负责区域的四周分布多个小观测点, 结合云 图、雷达观测以及计算机等进行综合分析, 极力确保数据精 确。充分利用 MICAPS, 该系统能够进行信息处理以及数据分析 工作, 目前我国普遍的天气预报模式就是分析天气图, 最常使 用的预报系统就是 MICAPS 系统, 它能够实现相关数据以及相 关信息的集合, 为更精确的天气预报提供参考,近期, 我国气 象现代化建设的重要部分就是启动开发此类系统。

3.4 强化天气预报队伍建设。预报业务人员是提高天气 预报准确率的关键, 目前预报工作对相关预报人员提出了多 方位要求, 既包含了分析实践整理天气状况的能力, 预报结 果修正、解释能力, 又包括了通过雷达、卫星等预报设备进 行资料整理和分析的能力。因此预报人员必须在工作中时刻 积累经验教训, 仔细研究阅读有关气象预警的书籍, 以提升 自身的专业技能。新进预报人员也要虚心学习, 不断求教, 以丰富预报经验和预报方法, 这是提高天气预报准确率的策 略。而且应制定出相关团队管理的制度, 进一步培养一支高
素质的预报人员队伍。预报员不仅要掌握预报预测的相关理 论方法与应用, 具备地理信息系统分析的能力, 还要了解综 合的气象技术。同时定期对预报业务人员进行培训, 积极选 拔优秀员工外出学习, 加强与其他地方专业人员的交流与沟 通, 提高自身的专业素养。积极引进专业素养比较高的优质 人才, 加强专业人才队伍对恶劣天气的分析观察能力, 通过 提高专业人员的实践分析能力、结果修改以及解释能力和复 杂数据分析能力, 来提高预报业务人员的专业素养。

3.5 加强极端恶劣天气预报系统建设。随着环境的不断 恶化, 地球温度不断升高, 部分地区极端恶劣天气频发, 因此, 要正确布局观测点, 积极引进雷达等先进的观测设备, 加强 极端恶劣天气预报系统建设。随着科学技术的不断发展, 恶 劣天气系统不断优化升级, 许多新型的观测设备最新的气象 卫星、雷达、闪电定位仪等可以组成一套完整的天气预报监 测系统, 这个系统提供出的数据也可以形成一个资料体系, 只要加以正确的科学分析, 就可以很大程度上提高准确率, 使天气预报朝着科学的方向发展。

\section{4 结束语}

综上所述, 天气预报对于人们的日常生活非常重要, 并 且提高天气预报准确率对避免或降低气象灾害所造成的损 失具有重要影响, 因此需要不断完善气象观测工作, 积极引 进先进的观测技术, 学习科学的气象预报技术, 不断加强极 端恶劣天气预报系统建设以及专业人才队伍建设, 从而发挥 天气预报的功能作用。

\section{[参考文献]}

[1]杨雪峰.天气预报在农业防灾减灾中的应用分析 [ J ] 中国新通信,2018,20(03):232.

[2]陈兴, 严娟. 提高基层台站天气预报准确率探究 [ J].海 峡科学, 2017,(02):37-38.

[3] 吴䑣,罗云凯, 李丹,等.关于提高天气预报准确率的思 考及建议[J].农村经济与科技,2017,28(21):245-246.

[4]高否.提高天气预报准确率的要点分析 [ J]. 南方农 业,2018,12(17): $161+165$. 